\title{
Arguments Used in Public Comments to Support or Oppose the US Department of Agriculture's Minimum Stocking Requirements: A Content Analysis
}

Lindsey Haynes-Maslow, PhD, MHA; Lauri Andress, PhD, JD; Stephanie Jilcott Pitts, PhD; Isabel Osborne; Barbara Baquero, MPH, PhD; Lisa Bailey-Davis, MA, RD; Carmen Byker-Shanks, PhD; Bailey Houghtaling, MS, RD; Jane Kolodinsky, PhD, MBA; Brian K. Lo, MPH, RD; Emily H. Morgan, PhD, MPH; Emily Piltch, MPD; Elaine Prewitt, PhD; Rebecca A. Seguin, PhD; Alice S. Ammerman, DrPH, RD

\section{ARTICLE INFORMATION}

Article history:

Submitted 25 April 2017

Accepted 14 December 2017

Available online 13 February 2018

\section{Keywords:}

Supplemental Nutrition Assistance Program (SNAP)

Food policy

US Department of Agriculture (USDA)

Content analysis

Healthy food

2212-2672

https://doi.org/10.1016/j.jand.2017.12.005

\begin{abstract}
Background In 2016, the US Department of Agriculture (USDA)'s Supplemental Nutrition Assistance Program (SNAP) Retailer Rule proposed several changes for SNAPauthorized retailers, including: requiring retailers to have at least $85 \%$ of their food sales come from items that are not cooked or heated on site before or after purchase; requiring stores to stock seven varieties of qualifying foods from four staple food groups; requiring stores to carry perishable foods in three of the four staple groups; requiring stores to carry six units of qualifying foods at all times (depth of stock); disqualifying multiple ingredient foods and accessory foods from counting toward depth of stock requirements.

Objectives To better understand arguments used to support or oppose the USDA's proposed rule that all SNAP-authorized retailers carry more nutritious foods.

Design We conducted a qualitative content analysis of a random sample of public comments posted to the US Federal Register (a publicly available database) in response to the USDA's proposed rule.

Participants/setting A random sample of $20 \%$ of all public comments submitted by individuals and organizations to the US Federal Register were analyzed $(n=303)$ for this study. Results Three main themes were discussed: 1) arguments used in opposition to the rule; 2) arguments used in support of the rule; and 3) facilitators to assist stores in implementing the rule. Some of the subthemes included focusing on definitions used in the rule, reduced food access caused by stores leaving the SNAP program, lack of space and equipment for healthy foods, and the potential for increasing healthy food access. Conclusions Nutrition and dietetics practitioners may be tasked with working with stores to implement healthy changes. Nutrition and dietetics practitioners must understand the role that the USDA has in food policy. In addition, understanding how federal food policy influences the environments in which dietetics professionals' clients are making food choices is important.

J Acad Nutr Diet. 2018;118(9):1664-1672.
\end{abstract}

\section{$\mathrm{T}$} HE SUPPLEMENTAL NUTRITION ASSISTANCE PROgram (SNAP) provides nutrition assistance to 47 million low-income individuals annually. SNAP offers benefits usable as cash for the purchase of certain foods, with the goal of alleviating food insecurity. ${ }^{1}$ Currently, SNAP recipients are able to redeem benefits from more than 260,000 participating retailers nationwide. ${ }^{1}$ Research shows that SNAP recipients perceive that the program successfully serves its primary purpose of assisting households to buy enough food to make ends meet and reduce food insecurity. ${ }^{2}$ However, nutritional challenges have persisted for SNAP recipients over the past century. First piloted in 1939, SNAP focused on supplementing protein-calorie insufficiency and reducing agricultural surpluses. ${ }^{3}$ However, currently SNAP recipients are confronted with the concurrent issues of obesity, chronic diseases, and food insecurity. ${ }^{4}$ Studies report that most SNAP recipients are relieved of caloric deficiency, but many have compromised dietary quality and do not meet the Dietary Guidelines for Americans. ${ }^{5,6}$ Greater access to calories derived from inexpensive, energy-dense foods and less access to more expensive, nutrient-rich foods ${ }^{7,8}$ may be one reason that low-income individuals are more vulnerable to diet-related chronic disease. ${ }^{9}$

In February 2016, the US Department of Agriculture (USDA) published draft rules that required all SNAP-authorized retailers to carry more nutritious foods, called "Enhancing 
Retailer Standards in the Supplemental Nutrition Assistance Program" (Table 1). The goal of the proposed rule was to increase access to healthier foods for SNAP recipients. The USDA's proposed SNAP retailer rule presented several potential changes to the stocking requirements, including requiring retailers to 1 ) have at least $85 \%$ of their food sales from items that were not cooked or heated on site before or after purchases; 2) stock seven varieties of qualifying foods in four staple food categories (meat, poultry, fish; bread or cereals; fruits or vegetables; dairy); 3 ) carry perishable foods in three of four staple food groups; 4) carry 6 units of qualifying foods at all times, and 5) prohibit multiple-ingredient foods (eg, sandwiches and TV dinners) and accessory foods (eg, pastries, soda, and condiments) from being counted toward the variety, perishables, or depth of stock requirements. In total, the proposed SNAP retailer rule would have required stores to carry a minimum of 168 required food items at all times. Previously, the USDA required stores to only carry a minimum of 12 items.

Federal agencies are required to publish notices of proposed rulemaking in the Federal Register, which notifies the public of a pending regulation..$^{10}$ Any person or organization may submit a comment. When agencies publish final regulations in the Federal Register, they must address the significant issues presented in comments and discuss any changes made in response to them. The USDA's proposed rule was posted in the Federal Register, and public comments were accepted until May 18, 2016..$^{10}$

Although the purpose of the proposed rule was to increase healthy food options available to SNAP recipients, stores can face barriers to stocking healthy food options, particularly fresh produce among small stores, including structural constraints, ${ }^{8,11}$ perceived low customer demand, ${ }^{11,12}$ perishability, ${ }^{11}$ and limited vendor supply ${ }^{13}$ and quality ${ }^{14}$ in rural areas. One concern regarding the proposed rule is that implementation barriers would discourage retailers from participating in SNAP. The purpose of this study was to better understand the arguments used in the public comments to support or oppose the USDA's proposed rule for stocking requirements, which would increase availability of more nutritious foods by SNAP-authorized retailers. Understanding stakeholders' perspectives on the proposed rule is critical to use in current and future SNAP policy formation and implementation. Therefore, this study was conducted as a part of a joint project among members of the national Nutrition and Obesity Policy Research and Evaluation Network (NOPREN 2016) Rural Food Access Working Group. ${ }^{15}$ This group shares an interest in how policy can impact rural communities and has a high level of expertise in this area. Therefore, members volunteered to analyze public comments.

\section{MATERIALS AND METHODS}

A total of 1,283 comments were submitted to the US Federal Register in response to the rule. As in many research studies, the study team was restricted by time and financial resources to analyzing all the comments; therefore, we downloaded a list of all of the comments and used a random number generator to select $20 \%$ of the comments to be analyzed $(\mathrm{n}=303)$. After selecting the public comments to be analyzed, we downloaded each individual comment electronically and

\section{RESEARCH SNAPSHOT}

Research Question: What arguments were used by stakeholders to support or oppose the USDA's proposed rule that all SNAP-authorized retailers carry more nutritious foods?

Key Findings: We conducted a qualitative content analysis of a random sample of public comments posted to the US Federal Register. Among 303 public comments, three main themes were discussed: 1) arguments used in opposition to the SNAP retailer rule; 2) arguments used in support of the SNAP retailer rule; and 3) facilitators to assist stores in implementing the SNAP retailer rule.

created a database that included the following information regarding each public comment submitted: submitter name, title, organization, and submitter type (ie, business, nonprofit, individual, government). A total of 303 nonduplicated public comments were downloaded separately, and the entire comment's content was analyzed. Institutional Review Board (IRB) approval was not required for this study because the US Federal Register is a publicly available database, and submitters are notified before their comments are uploaded that it will be placed on a publicly accessible website.

To help with anonymity, the research team created two separate data files: 1) an Excel sheet with a document identification number, commenter name, state, organization, and stakeholder type and then the Atlas.ti file that included only the text of the public comment. However, the public commenters' information was not uploaded into Atlas.ti (only the text of their public comment with the document identification number). Therefore, our coders did not see the individual's information (unless it was written as part of the public comment). After public comments were analyzed, we used the document identification number to help identify which organizations/individuals wrote which comments.

A codebook for this study was developed through an iterative process. In the initial coding phase, three researchers (L.H.M., B.B., and L.A.) independently applied open coding to 20 of the 303 comments identified. Researchers compared open codes, reconciled coding discrepancies, and then created a codebook that was applied to all 303 comments. Five coding pairs (R.S. and E.M.; E.P. and B.H.; L.H.M. and C.F.; C.B.S. and E.P.; B.L. and L.B.D.) were trained by the principal investigator regarding the codebook and coding procedures. Each pair independently coded approximately 45 comments. Code discrepancies were discussed, and consensus was reached within each coding pair. Code frequencies were then determined and summary reports for each code compiled.

A qualitative approach was used to analyze the public comments. Researchers chose to conduct a thematic content analysis. Because this approach is a data-driven research strategy, theory is not always needed to conduct this analysis. Thematic content analysis is a common qualitative approach because it allows researchers to examine and record patterns (known as themes) based on the data. ${ }^{16}$ Thematic content analysis is considered an inductive approach to analyzing qualitative data because researchers create themes as they emerge from the data. ${ }^{17}$ This is considered an appropriate 


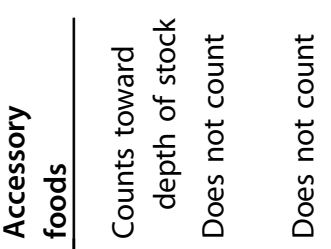



잉

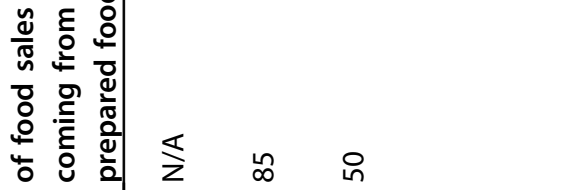

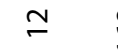

$\stackrel{\infty}{\infty}$
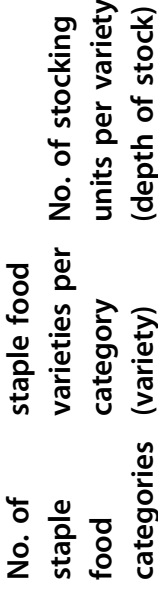

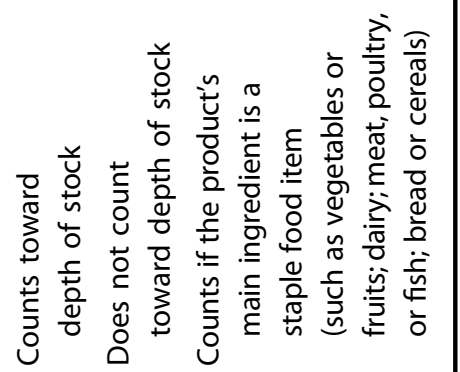

approach to analyzing public comments because it allows for the capturing of themes that might have been overlooked if using a preestablished codebook with themes already created. In addition, it goes beyond code counting and focuses more on the interpretation and meaning of themes. ${ }^{18}$ Public comments were analyzed using Atlas.ti version 7.0. ${ }^{19}$ Frequency of arguments was calculated based on the number of times a theme or subtheme was mentioned in a comment; this resulted in the same argument potentially being coded multiple times in one comment.

\section{RESULTS}

Six types of submitters wrote public comments to the Federal Register in response to the proposed rule: 1) retail food businesses, 2) government, 3) education, 4) hospitals and health care, 5) nonprofit organizations, and 6) private citizens (Figure). These categories are similar to the USDA's final analysis of all comments submitted to the in response to the rule. $^{20}$ Among those main categories, nine subcategories were created. These were nested under three of the submitter groups, namely businesses, government, and nonprofit organizations. The subcategories were as follows: businessesagriculture and retail food industry; government-local government, state government, the legislative branch, and federal agency; nonprofit organizations-food and nutrition (eg, food banks and hunger organizations), labor unions, and policy. Nearly half of all comments were submitted by retail food businesses (49.5\%). Private citizens submitted $21.6 \%$ of the public comments, followed by hospitals and health care (13.0\%); nonprofit organizations (7.6\%); government (5.6\%), and the education sector (2.7\%).

Among the 303 public comments submitted by stakeholders, three main themes were discussed (listed from most frequently cited to least): 1) arguments used in opposition to the SNAP retailer rule; 2) arguments used in support of the SNAP retailer rule; and 3) facilitators to assist stores in implementing the SNAP retailer rule (Table 2).

\section{Arguments against the Rule}

"Arguments against the rule" were mentioned a total of 1,302 times, and the 10 most commonly cited subthemes (listed from most frequently cited to least) were: 1 ) concerns over specific rule requirements such as depth of stock and staple food definition; 2) reduced food access because of stores withdrawing from SNAP; 3) reduced profit margins because of proposed requirements; 4) doubting the effectiveness of the rule in improving diets because of lack of healthy food demand by SNAP recipients; 5) space concerns for where to put all of the required food items; (6) perishability of staple food items; (7) ambiguity of language in the rule; (8) government interference with the free market principles of supply and demand; (9) supply chain distribution concerns and ordering infrastructure needed to purchase and store staple food items; and 10) lack of equipment and supplies to store staple food items. Table 2 shows code definitions and frequencies.

Most arguments (30.0\%) used to oppose the rule were submitted by businesses and focused on the specific rule requirements, including depth of stock, multiple food ingredients, and definition of a retail food store. Several comments indicated concern about the proposed definition of 


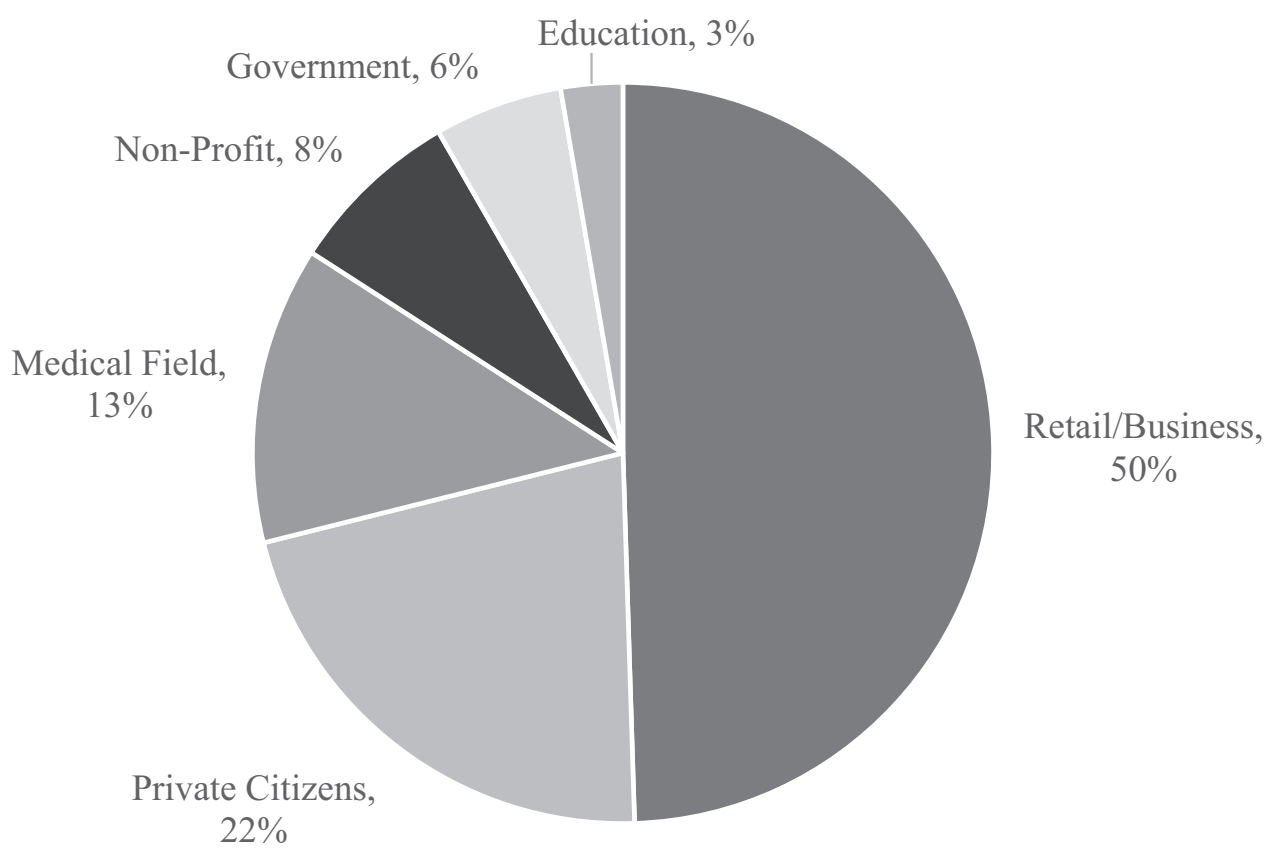

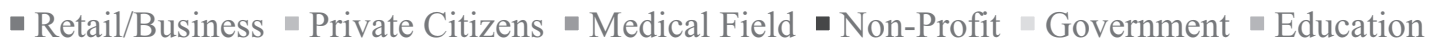

Figure. Percent of public comments analyzed by type of commenter, $\mathrm{n}=303$.

variety. In addition, businesses were concerned with the continued ability of SNAP recipients to use their SNAP benefits to purchase accessory foods. Some businesses provided suggestions for adjusting the definition of variety and including specific language related to the continued eligibility of nonstaple items. Other comments opposed the proposed approach to classifying multiple-ingredient foods and argued that these foods should count as staple foods. One retail business owner wrote:

To me it doesn't make sense the proposed regulations would make our pizza not eligible for SNAP purchases. The USDA law states that SNAP benefits are allowed for the purchase of bread, fruits, vegetable and dairy, isn't the pizza a combination of all of the above?

One opposition argument highlighted the sentiment that the proposed rule unfairly targeted small retail food outlets. One comment from a retail business owner said that he understood the intent of the proposed rule, but he would be forced to choose between his business and accepting SNAP: "I support implementing the Congressional requirement to increase staple and perishable food minimums, but I oppose the other parts of the proposed rule. If you do not revise the rule to fix these problems, my company will no longer be able to participate in SNAP." With the proposed rule requiring 168 staple food items to be continually stocked, many small stores were concerned that they would not have the space required to comply ( $n=101)$. Another retail business owner noted:

Our average store size is 2000 sq. feet or less. Most often there is no backroom storage and we rely on store sales floor to keep enough stock for each items. We mostly get our deliveries to replenish stock once a week. Stocking $168+$ items across 4 staple food categories would put too much burden on retailers like us with small footprint stores.

Retailers were also concerned that the proposed depth of stock requirement would lead to increased food waste because of having to discard perishable items by their "sellby" date if customers did not purchase them $(n=33)$. On a related note, some comments indicated that perishable items often arrive at stores in poor condition or near to their labeled sell-by date. Some store owners expressed that geography and transportation issues inhibited their ability to source staple food items. Another sentiment shared by retail business owners was that additional cold storage would be required and that the cost of installing and running the necessary equipment may preclude some stores' involvement in the program:

I think it would be a mistake to require small, neighborhood convenience stores that accept SNAP to carry fresh produce, dairy and meat. While access to those foods is absolutely desirable, the burden of installing the cooling required and the cost of dealing with spoilage might prevent some stores from complying, which means they lose SNAP.

\section{Arguments Supporting the Rule}

Arguments in support of the USDA's rule were mentioned 556 times (28.5\% of all themes). Most stakeholders 
Table 2. Themes and sub-themes discussed in public comments ${ }^{\mathrm{a}}$ and their frequencies, United States 2016

\begin{tabular}{|c|c|c|c|c|}
\hline Theme & Sub-theme & Definition & $\begin{array}{l}\text { Sub-theme } \\
\text { total, }{ }^{\mathrm{b}} \mathrm{n}(\%)\end{array}$ & $\begin{array}{l}\text { Theme total, } \\
\mathrm{n}(\%)\end{array}$ \\
\hline \multirow[t]{7}{*}{$\begin{array}{l}\text { Arguments against } \\
\text { the rule }\end{array}$} & $\begin{array}{l}\text { SNAPC retailer rule } \\
\text { definitions }\end{array}$ & $\begin{array}{l}\text { Stores' concerns about specific SNAP retailer rule definitions, including } \\
\text { retail food stores, multiple food ingredients, and staple foods }\end{array}$ & $391(30.0)$ & $1,302(66.8)$ \\
\hline & $\begin{array}{l}\text { Cost-benefit } \\
\text { argument }\end{array}$ & $\begin{array}{l}\text { Mentions how the new SNAP retailer rule hurts businesses by increasing } \\
\text { store costs, decreasing profits, and possibly reducing workforces as a } \\
\text { consequence of the rule }\end{array}$ & $259(19.9)$ & \\
\hline & Space concerns & Lack of space in store to adhere to depth-of-stock requirements & $101(7.8)$ & \\
\hline & Perishability & $\begin{array}{l}\text { Consideration of how long the item will keep fresh, ie, produce spoiling } \\
\text { too quickly }\end{array}$ & $33(0.025)$ & \\
\hline & Rule ambiguity & SNAP retailer rule needs to be more clearly defined & $31(0.024)$ & \\
\hline & Free market & $\begin{array}{l}\text { Government is interfering with free market principles of supply and } \\
\text { demand }\end{array}$ & $30(0.023)$ & \\
\hline & $\begin{array}{l}\text { Equipment and } \\
\text { supplies }\end{array}$ & $\begin{array}{l}\text { Concerns about lack of adequate equipment and supplies, including } \\
\text { coolers, refrigeration, and shelving }\end{array}$ & $18(0.014)$ & \\
\hline \multirow[t]{6}{*}{ Arguments for the rule } & Food access & $\begin{array}{l}\text { Mentions availability (presence of healthy food), accessibility (geographic } \\
\text { proximity and ability to travel to store), affordability (food prices), } \\
\text { accommodation (store hours or types of payment accepted), and } \\
\text { acceptability (individual attitudes or schedules) related to healthy food }\end{array}$ & $196(35.3)$ & $556(28.5)$ \\
\hline & $\begin{array}{l}\text { Access to the healthy } \\
\text { food }\end{array}$ & Increased access to healthy food because of SNAP retailer rule & $138(24.8)$ & \\
\hline & $\begin{array}{l}\text { Relationship between } \\
\text { nutrition and health }\end{array}$ & $\begin{array}{l}\text { Mentions the health benefits of healthy diet, consequences of unhealthy } \\
\text { eating (chronic diseases), and the obesity epidemic in the United States }\end{array}$ & $63(11.3)$ & \\
\hline & Nutrition & Improved nutrition attributable to SNAP retailer rule & $54(0.97)$ & \\
\hline & Health & Improved health outcomes attributable to SNAP retailer rule & $47(0.085)$ & \\
\hline & Time & The time it takes to shop, prepare, and cook healthy foods & $23(0.041)$ & \\
\hline
\end{tabular}




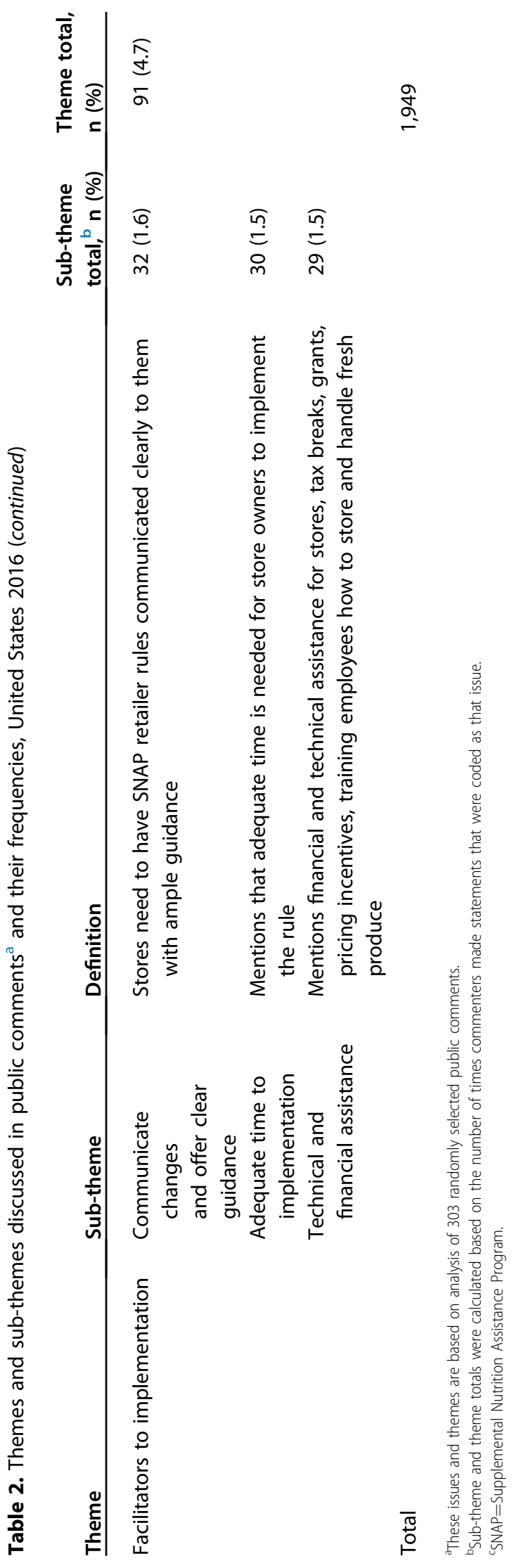

submitting these arguments were from hospitals and health care, nonprofit organizations, private citizens, and the education sector. Seven subthemes supported the rule (listed from most frequently cited to least): 1 ) general discussion of food access, 2) improving access to healthy food, 3) relationship between nutrition and health; 4) improved nutrition; 5) improved health; 6) the time required to prepare healthy foods, and 7) healthy food access is associated with intake.

A dietetics intern working in the health care and hospital sector discussing the importance of having improved access to healthy SNAP-authorized foods wrote:

Many parents have complained about the difficulty in obtaining nutritionally dense SNAP-approved foods such as fresh vegetables, fruits, and low-fat milk at local stores. Since many of these participants have limited access to transportation, they are forced to purchase undesired foods such as sugar-added beverages and prepacked meals.

Several comments $(n=23)$ argued that SNAP recipients have limited time for food preparation and rely on these multiple-ingredient items to feed their families. One comment submitted by a public health nonprofit organization stated: "The proportion of foods consumed away from home has increased, and many working families struggle to find the time and energy to prepare healthy meals from scratch."

Most comments were in support of the provisions of the proposed rule that would provide more variety of healthy foods to SNAP participants $(n=138)$. One comment from a template letter written by private citizens appeared five times:

I feel very strongly that we ensure that healthy foods, in particular, fresh fruits and vegetables are easily available to everyone. I strongly support this proposed rule requiring stores that accept SNAP to stock a wider range of food choices with a focus on fresh foods generally. Access to fresh fruits and vegetables is particularly challenging in what are known as "food deserts," and everyone should have access to fresh fruits and vegetables. Everyone deserves to have access to the foods that will keep them healthy.

\section{Facilitators to Implementation}

Facilitators to rule implementation were only used 91 times across the public comments (nearly $5 \%$ of all arguments). They focused on 1) clearly communicating changes and offering clear guidance about the rules to stores, 2) giving stores adequate time to implement, and 3 ) providing technical and financial assistance for some stores. Most comments offered suggestions to improve the proposed rule by providing various tools for store owners to understand the rule better and how to make changes to their stores accordingly $(n=32)$. One comment from a city's department of health stated: "To increase retailer compliance, we urge the USDA to initiate a comprehensive outreach strategy to communicate these significant changes to SNAP well in advance of the compliance date for these requirements, and to do so in a way that is accessible to all retailers."

Many comments supported a longer implementation timeline for smaller stores $(n=30)$. They suggested allowing store owners several years to phase in and complete 
adjustments to the proposed rule, including this comment from a nonprofit organization: "USDA should allow adequate time, beyond the 120 days in the proposed rule, for retailers to transition their operations to meet the new standards. This will require changes in the retailer's administrative and operations processes."

In terms of assistance for retailers, most comments $(n=29)$ suggested providing store owners with some kind of financial assistance to implement the proposed rule. Many store owners stated they would need to purchase or install new infrastructure to display and store the new food requirements outlined in the proposed rule. Other comments suggested providing store owners with additional training in various areas, such as how to handle and store foods to improve shelf life; effective marketing strategies to improve sales; and technical support to determine appropriate food products to stock.

\section{DISCUSSION}

In December 2016, the USDA promulgated the final SNAP retailer rule. It required stores to stock seven varieties in each of the four staple food groups, with three units of each variety (instead of the proposed six). ${ }^{21}$ It also eased restrictions on retailers from having $85 \%$ of food sales coming from items that are not cooked or heated on site to $50 \%$. The rule went into effect on January 17, 2017 and allowed retailers 12 months to comply. Newly authorized SNAP retailers would be required to implement the rule on May 17, 2017. If stores were located in high-need areas, such as reduced food access communities, and could demonstrate that they would have difficulty implementing the rule, they could apply for a "Need for Access" waiver. This waiver addressed the concern expressed in the public comments regarding stores withdrawing from SNAP because of the difficulty of implementing the new rule. ${ }^{21}$

Even though the final SNAP Retailer Rule went into effect January 2017, in May 2017, the federal government approved a federal budget that reopened a new SNAP Retailer Rule public comment period to discuss the definition of the term variety (see excerpt below from the budget legislation):

None of the funds made available by this Act may be used to implement, administer, or enforce the "variety" requirements of the final rule entitled, 'Enhancing Retailer Standards in the Supplemental Nutrition Assistance Program'...until the Secretary of Agriculture amends the definition of the term "variety"...Until the Secretary promulgates such regulatory amendments, the Secretary shall apply the requirements regarding acceptable varieties and breadth of stock to Supplemental Nutrition Assistance Program retailers that were in effect on the day before the date of the enactment of the Agricultural of $2014 .^{22}$

This legislative language delays implementation of the SNAP Retailer Rule until the Secretary of Agriculture reopens the public comment period and redefines the term variety. Ultimately, this makes the current SNAP Retailer Rule null and void and reverts it back to the pre-2016 standards (as shown in Table 1 ).

Regardless of the delayed implementation of the 2016

"Enhancing Retailer Standards in the Supplemental Nutrition
Assistance Program," this study showed that the business sector reported challenges within store settings to increasing the availability of healthy food options. Limited space, equipment, proper storage, time, technical assistance, and distribution channels were among the largest concerns for SNAP retailers. Results of this study showed that the final rule did consider businesses' concerns about the proposed depth of stock requirements and multiple-ingredient foods not counting toward the depth of stock. To help address some store owners' concerns about implementation barriers, the USDA created the "Need for Access" waiver. Similar to the SNAP retailer rule, when the revised Special Supplemental Nutrition Program for Women, Infants, and Children (WIC) Food package was released in 2009, concerns were expressed that stores would leave the program because of implementation barriers. ${ }^{23}$ However, researchers found that few stores dropped out of the WIC program because of difficulty meeting the minimum inventory requirements. ${ }^{23}$

The themes extracted from the public comments highlight the need for clear and effective communication from the USDA regarding exactly how to interpret definitions regarding staple food items, variety, and acceptable multipleingredient foods. Clear definitions of which foods satisfy the rule requirements, such as those provided in the Robert Wood Johnson Foundation Expert Panel Report "Minimum Stocking Levels and Marketing Strategies of Healthful Foods for Small Retailer Food Stores," ${ }^{24}$ along with examples of commonly qualifying foods, would be beneficial and would facilitate policy implementation. The Robert Wood Johnson Foundation report was just released in 2016, so formal analysis of how this report has assisted store owners is not yet available.

As in prior studies, skepticism about the effectiveness of the proposed rule to improve low-income SNAP participants' diets was expressed, ${ }^{11}$ along with optimism about the new rule promoting a healthier food environment in rural areas. However, when the WIC minimum inventory requirements changed in 2009 , studies demonstrated that WIC participants' diets also improved. ${ }^{25-27}$ This could be because the redeemable products changed, along with the minimum stocking requirements. For the new SNAP retailer rule to be effective, perhaps it must be accompanied by new rules related to what SNAP participants may purchase using SNAP benefits. Future studies could test whether increasing product demand using behavioral economic strategies results in increased consumer purchasing of newly stocked food products required by the final ruling. ${ }^{28}$

This study had several strengths. First, multiple coders were trained by the same lead investigator. In addition, this study allowed for the multiple coding of issues, and it examined a representative sample of public comments. Although researchers only selected a random sample of public comments to analyze, the origin of the comments submitted (ie, stakeholder type) were similar to the 1,260 public comments submitted to the USDA. In the USDA's full analysis, $72 \%$ of 1,260 public comments were from businesses, and the remaining $28 \%$ were from private citizens, trade associations, hospitals and health care, nonprofit organizations, and government. ${ }^{20}$ The main study limitation was that researchers could only analyze comments that were submitted to the US Federal Register-the beliefs voiced by 
these individuals or organizations may differ from those of individuals who did not submit a comment.

\section{CONCLUSIONS}

Federal policies regarding healthy food and food assistance programs will be proposed in the future, including the reopening of a new public comment period to define "variety" in the SNAP Retailer Rule. This study's findings could help guide rule implementation by understanding the likely stakeholder groups' viewpoints, need for technical assistance among stores, and need for in-store promotions and customer nutrition education to encourage choosing healthier items. Healthy food policies must consider store-level resource needs in tandem with system-level policy changes. Nutrition and dietetics practitioners may be tasked with working with stores to implement healthy changes. As similarly stated in Zizza's 2014 research editorial in the Journal of the Academy of Nutrition and Dietetics, ${ }^{29}$ nutrition and dietetics practitioners must understand the role of the Federal Register in refining and establishing food policy and how federal food policy influences the environments in which nutrition and dietetics practitioners' clients are making food choices.

\section{References}

1. SNAP Retailer Management 2014 Annual Report. US Department of Agriculture website. 2014. http://www.fns.usda.gov/sites/default/ files/snap/2014-SNAP-Retailer-Management-Annual-Report.pdf. Accessed May 7, 2016.

2. Leung C, Musicus A, Willett W, Rimm E. Improving the nutritional impact of the Supplemental Nutrition Assistance Program: Perspectives from the participants. Am J Prev Med. 2017;52(2): S193-S198.

3. Supplemental Nutrition Assistance Program (SNAP): A short history of SNAP. US Department of Agriculture website. 2014. https://www. fns.usda.gov/snap/short-history-snap. Accessed April 24, 2016.

4. Troy L, Miller E, Olson S. Hunger and Obesity: Understanding a Food Insecurity Paradigm-Workshop Summary. Washington, DC: The National Academies Press; 2011.

5. Andreyeva T, Tripp A, Schwartz M. Dietary quality of Americans by Supplemental Nutrition Assistance Program participation status: A systematic review. Am J Prev Med. 2015;49(4):594-604.

6. Leung C, Ding E, Catalano P, Villamor E, Rimm E, Willett W. Dietary intake and dietary quality of low-income adults in the Supplemental Nutrition Assistance Program. Am J Clin Nutr. 2012;96(5):977-988.

7. Darmon N, Drewnowski A. Contribution of food prices and diet cost to socioeconomic disparities in diet quality and health: a systematic review and analysis. Nutr Rev. 2015;73(10):643-660.

8. Andress L, Fitch C. Juggling the five dimensions of food access: Perceptions of rural low income residents. Appetite. 2016;105: 151-155.

9. Lin B. Diet Quality Usually Varies by Income Status. Washington, DC: US Department of Agriculture, Economic Research Service; 2005. Report No. 3.

10. A Brief History Commemorating the 70th Anniversary of the Publication of the First Issue of the Federal Register. US Office of the Federal Register. 2016. https://www.archives.gov/files/federalregister/the-federal-register/history.pdf. Accessed March 1, 2017.
11. Pitts S, Bringolf K, Lloyd C, McGuirt J, Lawton K, Morgan J. Formative evaluation for a healthy corner store initiative in Pitt County, North Carolina: Engaging stakeholders for a healthy corner store initiative, part 2. Prev Chron Dis. 2013;10:E120.

12. Pinard C, Shanks C, Harden S, Yaroch A. An integrative literature review of small food store research across urban and rural communities in the US. Prev Med Rep. 2016;30(3):324-332.

13. Palermo C, Gardiner B, Gee C, Charaktis S, Blake. A mixed-methods impact evaluation of the feasibility of an initiative in small rural stores to improve access to fruit and vegetables. Aust J Prim Health. 2017;22(6):545-553.

14. Byker-Shanks C, Ahmed C, Smith T, et al. Availability, price, and quality of fruits and vegetables in 12 rural Montana counties, 2014. Prev Chron Dis. 2015;12:150-158.

15. Rural Food Access Working Group. Nutrition and Obesity Policy Research and Evaluation Network (NOPREN) web site. 2017. https:// nopren.org/working_groups/rural-food-access/. Accessed March 15, 2017.

16. Braun V, Clarke V. "Using thematic analysis in psychology." Qual Res Psychol. 2006;3(2):83.

17. Guest G, MacQueen K, Namey E. Applied Thematic Analysis. Los Angeles, CA: Sage Publications; 2012.

18. Wilbraham L. Thematic content analysis: panacea for the ills of 'intentioned opacity' of discourse analysis? In: 1st Annual Qualitative Methods Conference: "A spanner in the works of the factory of truth." University of the Witwatersrand, Johannesburg. 1995. Unpublished paper retrieved from http://www.criticalmethods.org/wil.htm. Accessed May 16, 2017.

19. Atlas.ti. Version 7.0. Berlin, Germany; 2016.

20. Enhancing Retailer Standards in the Supplemental Nutrition Assistance Program (SNAP); 2/17/2016 NPRM. US Department of Agriculture website. 2016. https://fns-prod.azureedge.net/sites/default/ files/snap/ICF-Revised-Summary-Public-Comments.pdf. Accessed November 1, 2017.

21. Enhancing Retailer Standards in the Supplemental Nutrition Assistance Program (SNAP). US Office of the Federal Register website. 2016. https://www.federalregister.gov/documents/2016/02/17/ 2016-03006/enhancing-retailer-standards-in-the-supplementalnutrition-assistance-program-snap. Accessed December 1, 2016.

22. Consolidated Appropriations Act, Public Law No 113-79, Section 765, page 110 (2017).

23. Gleason S, Morgan R, Bell L, Pooler J. Impact of the Revised WIC Food Package on Small WIC Vendors: Insight From a Four-State Evaluation. Portland, ME: Altarum Institute; 2011.

24. Laska M, Pelletier J. Minimum Stocking Levels and Marketing Strategies of Healthful Foods for Small Retail Food Stores. Durham, NC: RWFJ Healthy Eating Research; 2016.

25. Andreyeva T, Luedicke J, Middleton A, Long M, Schwartz M. Changes in Access to Healthy Foods after Implementation of the WIC Food Package Revisions. New Haven, CT: Rudd Center for Food Policy and Obesity, Yale University; 2011.

26. Andreyeva T, Luedicke J, Middleton A, Long M, Schwartz M. Positive influence of the revised Special Supplemental Nutrition Program for Women, Infants, and Children food packages on access to healthy foods. J Acad Nutr Diet. 2012;112(6):850-858.

27. Schultz D, Byker-Shanks C. Houghtaling B. The impact of the 2009 Special Supplemental Nutrition Program for Women, Infants, and Children food package revisions on participants: A systematic review. J Acad Nutr Diet. 2015;115(11):1832-1846.

28. Gittelsohn J, Lee K. Integrating educational, environmental, and behavioral economic strategies may improve the effectiveness of obesity interventions. Appl Econ Perspect Policy. 2013;35(1):52-68.

29. Zizza CA. Policies and politics of the US Food Supply. J Acad Nutr Diet. 2016;116:27-30 


\section{AUTHOR INFORMATION}

L. Haynes-Maslow is an assistant professor and extension specialist, Department of Agricultural and Human Sciences, NC State University, Raleigh. L. Andress is an assistant professor, Department of Health Policy, Management, and Leadership, West Virginia University, Morgantown. S. Jilcott Pitts is an associate professor, Department of Public Health, East Carolina University, Greenville, NC. I. Osborne is an undergraduate student and A. S. Ammerman is a professor, Department of Nutrition, Gillings School of Global Public Health, both at the University of North Carolina at Chapel Hill. B. Baquero is an assistant professor, Department of Community and Behavioral Health, University of lowa, lowa City. L. Bailey-Davis is a research associate, Geisinger Center for Health Research, Geisinger Health System, Danville, PA. C. Byker-Shanks is an assistant professor, Food and Nutrition and Sustainable Food Systems, Montana State University, Bozeman, MT. B. Houghtaling is a doctoral student, Department of Human Nutrition, Foods, and Exercise, Virginia Tech University, Blacksburg. J. Kolodinsky is professor and chair, Community Development and Applied Economics, University of Vermont, Burlington. B. K. Lo is a doctoral student, E. H. Morgan is a post-doctoral associate, and R. A. Seguin is an assistant professor, Division of Nutritional Sciences, Cornell University, Ithaca, NY. E. Piltch is a doctoral candidate, Friedman School of Nutrition Science and Policy, Program in Agriculture Food and the Environment, Tufts University, Boston, MA. E. Prewitt is an associate professor, Department of Health Policy and Management, University of Arkansas, Little Rock.

Address correspondence to: Lindsey Haynes-Maslow, PhD, MHA, Department of Agricultural and Human Sciences, NC State University, Raleigh, NC. E-mail: Lhaynes-maslow@ncsu.edu

\section{STATEMENT OF POTENTIAL CONFLICT OF INTEREST}

No potential conflict of interest was reported by the authors.

\section{FUNDING/SUPPORT}

This research was supported by a grant from Healthy Eating Research, a national program of the Robert Wood Johnson Foundation. The views expressed here do not necessarily reflect the views of Healthy Eating Research or of the Foundation. This research was also supported through the Nutrition and Obesity Policy Research and Evaluation Network (NOPREN) by Cooperative Agreement Number 5U48-DP001911 from the Centers for Disease Control and Prevention. The findings and conclusions are those of the authors and do not necessarily represent the official position of the Centers for Disease Control and Prevention, or the National Institutes of Health, or the United States Department of Agriculture Food and Nutrition Service.

\section{ACKNOWLEDGEMENTS}

The authors thank Caroline Fisher and Lauren Greco for time as research assistants on this project.

\section{AUTHOR CONTRIBUTIONS}

L. Haynes-Maslow led the research study, including formulating the research question, designing the study, analyzing data, and writing the article. L. Andress helped create the codebook and writing the research article. S. Jilcott Pitts helped with formulating the research question and writing the article. I. Osborne helped with analyzing the data. B. Baquero helped created the codebook. L. Bailey-Davis, C. Byker-Shanks, B. Houghtaling, J. Kolodinsky, B. K. Lo, E. H. Morgan, E. Piltch, E. Prewitt, and R. A. Seguin helped analyze the data. A. S. Ammerman helped forum ate the research question and designed the study. 